Opinion

\title{
The global sport fishing industry and impact on the galapagos marine protected area
}

Volume 5 Issue 3 - 2017

\section{Opinion}

According to a report published by The World Bank in 2012, the global importance of fisheries is greatly underestimated. The fishing industry can be divided into three sectors the large, commercial operations aimed at making a profit small-scale subsistence or artisanal fisheries where the goal is survival; and recreational or sport fishing, which is fishing for pleasure. One of the most striking findings of The World Bank report is the under appreciated scale of the sport fishing sector.

"There are an estimated 225 million recreational fishers, or anglers, worldwide, almost twice the number of commercial fishers," the authors wrote. Conservatively, the sector generates over $\$ 190$ billion every year. In Costa Rica alone, foreign anglers brought in \$279 million in 2008 , representing $2.13 \%$ of the country's gross domestic product.

On this basis, there is a strong case for encouraging recreational fishing. For many fishermen, it offers a viable alternative to commercial fishing thereby reducing the pressure on already intensely harvested stocks. Sport fishermen can also provide additional eyes for patrolling and be required to report illegal commercial fishing vessels to the relevant authorities.

In the Galapagos Marine Reserve, the law is clear about what kinds of fishing are permissible. Commercial fishing is restricted to registered local captains. Artisanal fishing, variously referred to as "pesca vivencial", "pesca artesanal vivencial" or simply PAV, is permitted. Sport fishing or "pesca deportiva" is not.

In practice, however, recreational fishing in Galapagos is on the increase. A basic internet search turns up thousands upon thousands of hits. The reality is that approved and registered PAV fishers are permitted to conduct recreational fishing tours provided they abide by a "catch and release" system.

This highlights a discrepancy between the way that tourist activity is controlled on land and at sea. On land, visitors are restricted to clearly demarcated paths, with naturalist guides strictly enforcing regulations, prohibiting direct contact with wildlife, collecting, smoking and even flash protected area, the tourist-fishers who come from around the world to hook game fish including tuna, mackerel and wahoo have far fewer restrictions.

\author{
Jack Stein Grove \\ Senior Author of the Fishes of the Galapagos (Grove \& \\ Lavenberg, 1997), USA
}

Correspondence: Jack Stein Grove, Senior Author of the Fishes of the Galapagos (Grove \& Lavenberg, 1997), USA, Email grovejack509@gmail.com

Received: March 24, 2017| Published: March 27, 2017

The assumption is that "catch and release" of these sport fish is not damaging. Unfortunately there are no studies on the survival rates of exhausted marlin when released back into Galapagos waters. One of the successes of the Galapagos Marine Reserve is the haven it provides for sharks, but there is evidence from elsewhere that these top predators exploit weakened, bleeding billfish that have been stressed by a battle on the line.

Sport fishing poses a direct challenge to marine conservation. As I cautioned in the preface to The Fishes of Galapagos, first published almost 20 years ago, there should be no place for recreational fishing in a protected area like the Galapagos Marine Reserve. As things stand, with PAV fishermen offering sport fishing tours to tourists, there is a limit to the damage.

As the human population and number of visitors to Galapagos continue to increase, however, the Galapagos National Park must do all it can to prevent the escalation of this activity to the kind of scale that is seen in many other regions of the world.

\section{Acknowledgments}

None.

\section{Conflicts of interest}

None. 